\title{
Particularities of Orthodontic Treatment in Patients with Dental Anomalies that Need Orthodontic - Restorative Therapeutic Approach
}

\author{
LOREDANA GOLOVCENCU ${ }^{1}$, CRISTIAN ROMANEC ${ }^{1 *}$, MARIA ALEXANDRA MARTU1*, DANIELA ANISTOROAIEI ${ }^{1 *}$, \\ MARIANA PACURAR ${ }^{2}$ \\ ${ }^{1}$ Grigore T. Popa University of Medicine and Pharmacy, Faculty of Dental Medicine, 16 Universitatii Str., 700115, Iasi, Romania \\ 2University of Medicine and Pharmacy, Faculty of Dental Medecine, 38 Gheorghe Marinescu Str., 540139, Targu Mures, Romania
}

\begin{abstract}
Orthodontics is a specialty of dental medicine that discovers and treat dento - maxillary abnormalities (or lack of teeth alignment - malocclusions - unsightly dental rotation, lack of congruence of the two dental arches) solving both aesthetic and functional problems; contributes to improving dental and facial aesthetics, and implicitly to improving psychological well-being, self-esteem and quality of life. Orthodontic treatment is a support for multidisciplinary approach with other dental specialties in order to obtain facial and dental aesthetics; seeks to improve the appearance of smile and occlusion (bite) so that the teeth can bear without trauma the daily forces sore from the time of mastication; has the potential to eliminate future dental problems, including abnormal teeth wear. Dento-maxillary abnormalities synthesize current concepts of normal occlusion and explain the mechanisms by which dento-maxillary abnormalities occur, the morphological differences that allow classification and how they can affect the individual's appearance. The study includes a wider group of pediatric patients aged between 7 and 11 years, growing showing a diverse pathology, periodontal dental trauma, dental abnormalities, which may require the prosthesis. It can be argued that in most chromosomal syndromes, oro-facial abnormalities are major symptoms as pathognomonic value for clinical diagnosis; involvement of other body regions in these syndromes are frequently nonspecific and common to several syndromes. The great variability of their treatment measures used in dental abnormalities requires knowledge of their causal factors, as well as their mechanism of action and production.
\end{abstract}

Keywords:dento-maxillary anomaly, orthodontic treatment, trauma, prosthetics

During the embryonic development of the cephalic extremity, various anomalies may occur. Each stage of development can be stopped or deviated from normal due to certain factors, generating vices or congenital malformations. Importantfor the development of the dentomaxillary apparatus is the study of the growth and development of bone tissue; it allows the understanding of the bone changes and remnants that occur during the exercise of the different functions of the dento-maxillary apparatus[1-4]. The developmental tendencies of the bone tissue predominantly condition the deformations of the jaws that the dentist will have to correct. Bone tissue is characterized by a perpetual structural mutation; it is destroyed and rebuilt to adapt to various mechanical and functional influences; the bone substance is formed by impregnating the base substance with a protein-lime complex. The bone resorption process is carried out in two ways: osteolysis and osteoclase. The bone development and growth process is in continuous reshuffling due to exogenous and endogenous factors. One of the characteristics of life is its extraordinary variability [5-7]. This variability is more clearly manifested in the enormous numbers of life forms in the plant and animal regnum, from one-celled organisms to the most complicated creatures. The unit in this series is the species, which is a collective term for individuals with impressive genetic, morphological and psychological similarities. The similarity of different individuals of the same species is only relative, and there may be differences in detail[8-11].

The genotype can be changed to a greater or lesser extent by non-genetic influences. The great variability of treatment measures used in dento-maxillary abnormalities requires knowledge of their causal factors as well as their mechanism of action and production; there are genotypic abnormalities. Causes that act less frequently on the dentomaxillary device are congenital causes (number, shape, abnormalities of form, cleavings, dispositions), acquired causes (inflammation, trauma), eruption disorders [12-15]. The crooked teeth children will be future parodontopathic adults. Incorrect reports between the two dental arches may cause disorders that are manifested by poor mastication, muscle fatigue accompanied by joint pain. All of this can be prevented by orthodontic treatment, straining the teeth is not a fad but a necessity.ln the aetiology of anomalies, heredity occupies an important place, the views on it being still discussed[16-19]. The great thing to demonstrate the role of heredity lies with Korkhaus and Lundstron who, through their research on twins, regarding jaw development through serial models and radiographs, demonstrated the existence of fault (compressions of the jaw), thus revealing the role of heredity or the external environment before the function exercised the action[20-23]. Heredity influences the volume and shape of the teeth, tooth eruption, dental anomalies isolated and group position, shape and size of the jaw and mandible.Each individual has its hereditary heritage expressed in genes, the number of which has been multiplied by crossed races. The genes may or may not be influenced by environmental conditions either by inpulsion or by braking. The familial occurrence of the absence of single or bilateral lateral incisors, shape changes and microdontity[24, 25].The phylogenetic factors play an important role in the etiopathogenesis of dento- maxilation abnormalities.On the evolutionary scale, large transformations are observed in the dento-maxillary apparatus, also interested in maxillaries and teeth,

\footnotetext{
*email: cromanec@gmail.com; alexandra_martu@yahoo.com; daniela.anistoroaiei@umfiasi.ro
} 
transformations explained by the modification of the living conditions and especially of the alimentation. There is a discordance of the evolutionary rhythm between alveolar arches and teeth. Dento-alveolar dysregulation will manifest in the form of dento-maxillary abnormalities such as dento-alveolar incongruence, raiding accidents of wisdom teeth, the presence or disappearance of cusps. The endocrine glands play a special role in the development of the dento-maxillary apparatus, with early influence on skeletal development, in general, and on the maxillary bones, in particular. Hyperfunction and hypofunction of endocrine glands are often responsible for disorders installed at thedento -maxillary level.By their action, the glands particularly influence the processes of growth and development of the jaw and teeth[26,27].The necessary input of food principles varies with the age of the child, with the physiological state of the body. It is well known that any imbalance in essential food principles (proteins, sugars, carbohydrates) can generate general pathological conditions, which also resonate on the dentomaxillarysystem. A special role in the development of the facial skeleton and dental buds, has the metabolism of mineral salts as well as vitamins (vit.D). The basic functions of the dento-maxillary apparatus play a special role in the processes of their growth and modeling, while at the same time they can play a special role in the etiology of dentomaxillary abnormalities[28].

On the other hand, the balance between theintra and extraoral muscles, stimulating the harmonious development, in all planes, of the maxillary bones. Of great importance for the good development of the dentomaxillary apparatus is the masticatory value of the food. The food processing barrel that came with civilization has led to an insufficient use of the masticatory system, which is responsible for the development and grow th of the dentomaxillary apparatus. The use of strong consistency foods makes the phenomenon of physiological abrasion, thus allowing the avoidance of blocked occlusions and the realization of the second mandibular prosthesis[29,30].The use of soft foods calls for a low effort for the child, a less masticatory act as a duration, thus generating muscle hypotonia, abnormal cuspidal slides, the appearance of blocked occlusions and distal occlusions. The treatment of dento-maxillary abnormalities is an orthodontic treatment that will aim at restoring the physiognomy and function of the dento-maxillary apparatus, which requires perfect correlation and harmonization between the dental arches so as to achieve a normal occlusion, "aesthetic optimal functional" [.Dento-maxillary abnormalities that cause problems in the development of permanent denture and occlusion are: severe open occlusion, deep occlusion, particularly collapsed, distal occlusion, frontal inversion and inverse angles, cross-over occlusion by laterodeviation $[31,32]$.

\section{Experimental part}

\section{Materials and methods}

The study includes several children, ages 7 to 11 years, with a varied pathology, of which dento-periodontal traumas, dental abnormalities that may require prosthesis. We selected 9 children with dental anomalies, of which 7 dento periodontal traumas. The orthodontic and periodontal clinical evaluation, and through complementary examinations, allowed a classification of the periodontal pathology in the respective group, depending on the possible etiological factors and the form of manifestation.

\section{Results and discussions}

Dental prosthesis brings together all those replacements that restore the lost functions through the absence of teeth. Depending on the number of teeth remaining in the arcade, the type of complication that has occurred, represented by the vertical or horizontal tooth migration, a particularly important role with present articulation problems, chooses fixed or mobile restorations. Dental prosthesis analyzes the condition of dental arches and muscle and articular balance, often severely altered by loss of one or more teeth (edentation) or even excessive dental curing, and finds the most appropriate treatment solutions in the purpose of restoring the integrity of arches in a functional and aesthetic way in perfect harmony with the other structures of the oral cavity.

The reconstruction of the structures that make up the facial massif and the psychological development influences the conception and conduct of the prosthetic treatment. Teeth can be affected during children's play with rollers, bicycles, swimming pools, in the park, damage to the dental crown and / or root. There are also situations when the tooth can become mobile, it can be pushed partially or completely into the gum, or it can even be thrown out (completely out of the alveolus).

Dental trauma can be treated, but it is well known that complications can appear thereof; they need urgent treatment and should not be delayed, as both local and general complications may occur. In addition to impairing functionality, physiognomy, permanent tooth buds (in the case of traumas caused at the level of temporary teeth), they also produce aesthetic and emotional effects for the child. Depending on the trauma, some children need some specific radiographs and tests, as a result of which the doctor can see if there are fractures of the bone, root or tissue lesions. The traumatized child presents: pain or sensitivity (hot, cold or pressure) ; fractured tooth is mobilized or off; bleeding is for more than $10 \mathrm{~min}$; difficulty in swallowing or difficulty breathing; fever or signs of inflammation. Dentoalveolar traumas must be treated very seriously, as they can sometimes alter and have irreversible effects on the dentition; when these injuries occur in childhood, so during the deciduous dentition (temporary), the implications are quite serious. The damage to definitive dental buds can occur directly through the intrusion (clogging into the alveolus ) of the temporal tooth, or indirectly by the septic pulp complications caused by the mortification of the temporal tooth (nerve dies dental necrosis - at some point infection of the morphed pulp content with the appearance of a dental gangrene; this gangrene then transcends the canalicular space and reaches the bone, causing an inflammation of infectious origin, that is, an apical periodontitis. Traumas in childhood can affect growth and functionality, causing severe facial deformity. The incidence of deviation of the median line to the fractured part and the degree of deformity are related to the fracture site, the disturbance of the growth being more evident when the fracture is closer to the condyle head than in cases of mandibular fracture. Blackwood suggests that the most important predisposing factor is the articular hematoma due to the vasculature delivered in this setting, particularly in young children.Establishing a diagnosis and treatment plan requires the association of the data provided by the clinical examination with those of the paraclinical examinations.By clinical examination and observation records of the lot of children, aimed to analyze the causes associated with the need to apply the prosthetic 
treatment in growing patients and determine the frequency of required prosthetic treatment and applied at the level of the permanent teeth. The therapeutic complexity of this patient population, generated by etiological factors, individual peculiarities, behavioral characteristics dictated by age, changes in oral and facial structures as a result of the growth process as well as the increased duration of treatment is a challenge for the dentists. The main objective of this paper is to evaluate the causes that lead to the necessity of introducing a prosthetic treatment in the case of growing patients, to highlight the consequences of nonprotection, as well as theidentification of treatment solutions in children with trauma. It was followed from the etiological point of view the associated effects that determine the necessity of applying prosthetic treatment, the analysis of the causes associated with the necessity of applying prosthetic treatments to the growing patients , modalities of prosthetic restoration, and determination of the frequency of prosthetic treatment required and achieved at the level of permanent teeth. Orthodontics offers, on the one hand, therapeutic alternatives for dental prosthetics, as well as solutions for the optimization of the support, aesthetics, dental prosthesis reliability. In reverse, the dentures can solve some teeth position abnormalities or sometimes stabilize the results of the orthodontic treatment.This is done gradually, without any contradictions; their treatment sessions should be short and painless; is performed under general anesthesia, in the case of very young children, with physical / mental disabilities, totally non-cooperative with extensive dental treatments.Dental age allows you to appreciate the optimal moment of prosthetic treatment .Dento-parodontal traumas are common in temporary dentition and in permanent dentition, comprising age groups of 1-3 years, 7-12 years old. The most affected are the upper incisive lateral, inferior teeth, central incisors, inferior lateral incisors and upper lateral incisors. The clinical models of dentoperiodontal trauma in temporary dentition where prosthetic treatment is required, are: avulsion, extrusion, intrusion, lateral dislocation, root fracture.Prosthetic dental treatments are indicative of the following traumas: coronary artery fracture, penile coronary fracture, root coronary fracture. The dental anomalies of development requiring prosthetic treatments are: anodontia, microdontia, macrodontia, reinclusion, diastema, transposition, imperfect amelogenesis, dentin dysplasia, Turner syndrom.

The institution of orthodontic treatmentand, depending on the clinical form, of periodontal therapy does notal ways ensure the restoration of a normal periodontal status either due to incrimination and other etiological factors, or due to irreversible injuries.Periodontal pathology diagnosed at the age of growth is one of the major indications of periodic orthodontic surveillance or institution of orthodontic treatment associated with periodontal therapy specific to this age group.In order to redress dento- maxillary abnormalities, the orthodontic appliances are used to restore the normal balance between the dental arches or the vicious positions of the teeth. The correct position of the teeth and arches is important for preserving the health of the child's body, preventing possible outbreaks, preventing the disease of the dental support tissue, thus preventing the parodontopathy that many young people suffer of, while contributing to the restoration of the correct physionymy and phonation .Fixed orthodontic appliances are more effective because the child, unable to remove them, will always wear them, the device will work indefinitely, the disadvantage being physiognomic, when the child is in school or in a community.

The mobile type gives an esthetic advantage, because the device can be taken out and up at certain times of the day, but often the child forgets or want to forget it and put it in his mouth and so his time driving is greatly diminished, so the results will be weaker in the time unit than with the fixed ones. In the case of children where we primarily pursue the therapeutic goal, fixed devices are the most recommended for their efficiency.Orthodontic treatment is a treatment of long duration, a comprehensive treatment that is associated with miogymnastics to strengthen the muscles around the oral orifice and correlation with the muscle fibers of the tongue and pharinge. It should be carried out breathing exercises, too, movement, head position correction and the muscles of the neck and the vertebral gutters

\section{Conclusions}

The dento-maxillary device in the process of growth and development is modeled under the influence of functions, a normal course of basic functions (mastication, swallowing, breathing and phonation) will ensure a balanced development.The possibilities and limits of orthodontic treatment are conditioned by the shape and size of the basal bone of the two maxillaries genetic determinated. Prosthetic restaurations must adapt and stimulate the normal development of jaw bones.

\section{References}

1.BABAJI P. Crowns in Pediatric Dentistry. 1st ed. Ed. Jaypee Brothers Medical Publishers: New Delhi; 2015. p 21-133.

2.BASNO A, MAXIM A, SAVIN C, BALCOSC, TATARCIUC MS. Prevalence Of Edentulism And Related SocialBehavioural Factors Among Young Adults Of Iai, Romania. International J ournal of Medical Dentistry. 2016; 6(3): 214-22

3.BOBOCGH. Aparatuldento-maxilar. Formare si dezvoltare. ed. A IIa. ED. Medicala: Bucuresti; 2009: 7-315.

4.CAMERON A, Widmer R. Handbook of Pediatric Dentistry. 4th Ed. Ed. Mosby Elsavier: 2013; 9-25, 47-63, 149-209, 269-409

5.DANTAS L.R., GOMES M.C., DANTAS L.R., CRUZ-DA-SILVA B.R., DE PERAZZO1 M.F., SIQUEIRA M.B.L.D., PAIVA S.M., GRANVILLE-GARCIA A.F. The impact of dental treatment on oral health-related quality of life among preschool children. J Public Health 2015; 23: 327-31 6.DAVID DV. Morfologie dentara. Curs. Bucure'ti: 2003: 96-109 7.DOROBA VALENTINA, STANCIU D. Ortodonie si ortopedie dentofaciala. Ed. Medicala :Bucuresti:;2011: p 15- 55, 489-93

8.FEIERABEND S, KLAIBER B, HELLWIG E. Laboratory-made composite resin restorations in children and adolescents with hypoplasia or hypomineralization of teeth. Quintessence Int. 2012; 43: 305-11.

9.FORNA N - Protetica Dentara. Vol. I, Ed. Enciclopedica: Bucuresti; 2011: p 88-147, 147-401.

10.BELCHEVA AB, FILIPOV IA. Restoration of Fractured Permanent Teeth in Children with Composite Resin Veneers. Balk J Stom. 2011; 11.FRATILAA, SABAU M, MARZA D, BOITOR C, CRISTIAN A, SOBOTEAC A, BOITOR O. The Consequences Of Early Loss Of The Six Year Molar On The Dento-Maxillary System Development. ActaMedica Transilvanica 2011; 16(3): 441

12.HEASMAN P, MCCORD JF, GRANT AA, YOUNGSON CC, WATSON RM, DENISDM. Master Dentistry vol 2. Restorative Dentistry, Paediatric Dentistry and Orthodontics. Ed. Churchill Livingstone: London; 2003: p 169-227

13.HOLMES JD.Considerations in Dental Implant Placement in the Young Patient: A Surgeon's Perspective. Semin Orthod 2013;19:24-36. 14.IONESCU E, MILICESCU ID, POPESCU M, POPOVICIU O, MILICESCU V. Ortodonie si ortopedie dento-facialã. Ghid clinic si terapeutic. Ed. Cermaprint: Bucuresti; 2001. 
15.MAHROUS MS, BHAYAT A, HIFNAWY T, BEKKER H, AHMAD MS. Can the prevalence of dental caries be used as an indicator of the quality of dental services? A cross-sectional study among children in AlmadinahAlmunawwarah, KSA. J ournal of Taibah University Medical Sciences 2016; 11(1): 41-533.

16.MARWAHA M, BHAT M, NANDA KDS. Building-up a Smile in a 5Year-Old Child: A Case Report. International J ournal of Clinical Pediatric Dentistry, 2012; 5(2):151-4

17.MONACO C., CARDELLI P, BOLOGNESI M, SCOTTI R, OZCAN M. Inlay-retained Zirconia Fixed Dental Prosthesis: Clinical and Laboratory Procedures. The European J ournal Of Esthetic Dentistry 2012. 7(1): 48-60.

18.PINCHI V, DE LUCA F, RICCIARDI F, FOCARDI M, PIREDDA V, MAZZEO E, NORELLI GA. Skeletal age estimation for forensic purposes: A comparison of GP, TW 2 and TW 3 methods on an Italian sample. Forensic Science International 2014; 238: 9083-84 40

19.PRIYADARSHINI C, PURANIK MP, UMA SR. Dental Age Estimation Methods: A Review. International J ournal of Advanced Health Sciences 2015; 1(12): 19-25

20.SANDU SA, PAUNA MR. Protetica Dentara. Curs. Ed. Cermaprint: Bucure'ti; 2007: p 50-73, $147-152$

21.TURP JC, SCHINDLER $H$. The dental occlusion as a suspected cause for tmds: epidemiological and etiological considerations. J ournal of Oral Rehabilitation 2012; 39(7):502-12

22.VINEREANU A. Conceperea si conducerea tratamentului protetic în dentiia temporarã si mixta. Ed. Cermaprint: Bucuresti; 2005: p 9121

23.WYNE AH. CARIES PREVALENCE, Severity, and Pattern in Preschool Children. The J ournal of Contemporary Dental Practice. 2008; 9(3): 24-31
24.CIURCANU O.E, FORNA, D.A., POPA C., SCUTARIU M.M. Implementation of methods of loco-regional anesthesia in dental surgery, Romanian journal of oral rehabilitation, Vol. 9, Issue: 4, 2017. Pg. 120-127

25.SCUTARIU M.M., CIUPILAN C., SALCEANU M., MELIAN A., FORNA D.A, SIOUSTIS I., CIURCANU O.E., Incidence of dento-periodontal pathology in geriatric patients, Romanian journal of oral rehabilitation, Vol. 10 (1), 2018. Pg. 128-132

26.BELEI,D.,FORNA,N.C.,SANDU,I.,et al., Novel Mesoionic 2-Methy14-(1,3-Dithiol-2-yllum)phenolates, Rev. Chim.(Bucharest), 65, no. 1, 2014, p. 80-83

27. ANTOHE,M., AGOP FORNA,D.,ANDRONACHE,M.,et al., Aspects of the therapy of partially extended edentation using modern methodsattachements as maintenance,support and stabilization,Romanian Journal Of Oral Rehabilitation, 8 (2), 2016, Pages: 16-25

28.CIOCAN-PENDEFUNDA,A.A.,MARTU,M.A.,ANTOHE,M.E.et al.,Indirect composite veneers as a social therapeutic solution.A case report, Romanian Journal Of Oral Rehabilitation, 10, (4), 2018 Pages: $91-96$

29. PETCU,A.,SAVIN ,C.,BALAN,A.,Biomaterials involved in frontal area restorations in pediatric dentistry,Biomaterials Involved in Frontal Area Restorations in Pediatric Dentistry,Rev.Chim.(Bucharest), 69 , no. 12 , 2018, p. 3473-3476

30.EARAR,K.,ANTONIAC,V.I.,BACIU,S., Etching Treatment Effect on Surface Morphology of Dental Structures,Rev.Chim.(Bucharest), 68, no. 11,2017, p. $2700-2703$

31.DROCHIOI,C., COSTAN,V.V., ZAHARIA, M., et al., FT-IR Characterization of Some Biological Materials Used in Reconstructive Surgery, Rev.Chim.(Bucharest), 66, no. 9, 2015, p. 1302-1305

32.HRISTIAN, L., BORDEIANU, D.L., IUREA, P., et al., Study of the Tensile Properties of Materials Destined to Manufacture Protective Clothing for Firemen, Mat. Plast., 51, no. 4, 2014, p. 405-409

Manuscript received: 6.02 .2019 